\title{
MATHEMATICAL
}

GAZETTE

EDITED FOR THE MATHEMATICAL ASSOCIATION BY

R. L. GOODSTEIN

WITH THE ASSISTANCE OF

H. M. CUNDY K. M. SOWDEN

\section{FEBRUARY 1956}

Vol. XL No. 331

Curves of Pursuit by R. H. Macmillan

Rational Analogues of the Logarithm Function by J. Lambek and L. Moser

The Harmonic Logarithm by M. F. Egan

The Power of a Point for a Curve by E. H. Neville

Film Groups by T. J. Fletcher

A Digit Transformation by E. Goodstein

The Problem of the Thirteen Spheres by J. Leech

An Analysis of Errors appearing in a Test on Algebraic Fractions by W. O. Storer

The Simple Pendulum at any Amplitude by P. J. Bulman

Farey Series and Stern Series by C. G. Paradine

Unified Mathematics or Mathematics as a Unity by N. E. W. Chapman

Mathematical Notes (2585-2596). H. ApSimon ; F. Brierley ; H. R.

Chillingworth ; L. E. Clarke ; M. F. Egan ; R. L. Goodstein ;

H. Perfect ; A. G. Sillitto

Pseudaria (8-11). A. J. Howie ; E. A. Maxwell

Problem Bureau

Reviews. L. D. Adams ; L. S. Bosanquet ; T. A. A. Broadbent ; B. C. Brooks ; B. M. Brown ; H. M. Cook ; H. Davenport ; A. Fletcher ; R. L. Goodstein ; W J. Hodgetts ; M. Hutton ; A. J. Macintyre ; C. G. Paradine ; L. A. Pars ; H. T. H. Piaggio ; W. W. Rogosinski , F- Sandon ; B. A. Swinden ; F- Ursell ; S. Vajda ; T. J. Willmore 


\section{SCHOOL MATHEMATICS}

by H. E. PARR, M.A. Part 1. 7th Edition. 8s. 6d.; with answers, N 9s. 3d. Or in two sections, $A$ and B, 5s. each. Part ii. 7th Edition.

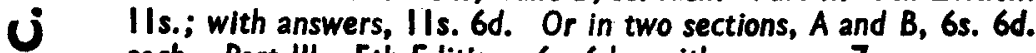
each. Part III. 5th Edition. 6s. 6d.; with answers, 7s.

"A book which many teachers will want to try with their classes ... the bookwork and examples are models of their kind. The type and layout are excellent, the many illustrative diagrams are bold and clear." JOURNAI OF EDUCATION.

\section{SCHOOL GEOMETRY AND TRIGONOMETRY}

by C. V. DURELL, M.A. 4th Edition. 10s. 6d. Also in parts. "We commend this textbook unreservedly to those teachers who are on the outlook for a course in geometry and trigonometry which combines practical and theoretical elements with the minimum of formalism." scoTTISH EDUCATIONAI JOURNAL.

\section{ELEMENTARY ANALYSIS}

by A. DAKIN, M.A., B.Sc., and R. I. PORTER, M.A. 10s. 6 . This standard book, now in its 14 th Edition, provides a very suitable year's work for the first year in the VIth form. "Very lucid and well-arranged, and the numerous examples provide excellent practice for both average and more advanced pupils." THE A.M.A.

\section{FURTHER \\ ELEMENTARY ANALYSIS}

by R. I. PORTER, M.A. 5th Edition. Demy 8vo. 21s. net. Completes a two-year Sixth Form course in Pure Mathematics suitable for all but the mathematical specialist. A SENIOR MATHEMATICS MASTER writes: "I have been teaching now for 40 years. All that time I have been looking for a good Analysis book. At last, I think, I have found it. Please pass on my congratulations and thanks to Mr. Porter for giving us such a fine textbook." 